\section{Isolation, biotyping and antimicrobial susceptibility of Campylobacter isolates from raw milk in Erbil city, Iraq}

\author{
Dhary Alewy Almashhadany \\ Knowledge University Research Center, \\ Erbil, Kurdistan Region, Iraq
}

\begin{abstract}
This study aimed to determine the prevalence and antimicrobial sensitivity of Campylobacter species in raw milk sold at retail vending in Erbil city. Three hundred and fifty (350) samples were aseptically collected from retail raw milk shops between January and June 2019. For isolation of Campylobacter spp., samples were cultured on selective media and tested for biotype and antimicrobials susceptibility by disk diffusion assay. The overall prevalence of Campylobacter spp. was $12.6 \%$. Campylobacter jejuni was significantly prevalent (65.9\%) among other Campylobacter species. Antimicrobial susceptibility testing showed complete sensitivity to tetracycline, rifampicin, and neomycin. On the other hand, total resistance to ampicillin and trimethoprim was observed. Strikingly, as low as $56.8 \%$ and $72.7 \%$ of isolates are still sensitive to the drugs of choice in campylobacteriosis treatment; ciprofloxacin and erythromycin respectively. This resistance pattern of Campylobacter found in this study is critically alarming owing to the insusceptibility to the aforementioned antibiotics commonly used as the drugs of choice for campylobacteriosis treatment. Increase in Campylobacter prevalence in raw milk was associated with warm season. These levels prevalence and resistance worth further investigations and effective countermeasures owing to potential public health hazards.
\end{abstract}

\section{Introduction}

Campylobacter is a zoonotic gram negative small curved or S-shaped bacterial pathogen. It is recognized globally as the most public cause of bacterial milk-borne diseases. Since its first taxonomic validation, the genus Campylobacter has developed to comprise several vital human and animal pathogens. It has been the most recurrent pathogen isolated in outbreaks in both developed and developing countries throughout the past decades (Kaakoush et al., 2015). Campylobacter species are hyperendemic in several developing countries due to abundant natural reservoirs, poor environmental sanitation, reduced food hygiene and safety, close contact with animals at domestic settings in rural and agricultural populations, among various other factors (Isabel, 2019; Kaakoush et al., 2015). Various species of Campylobacter are common component of the intestinal microbiota of a wide range of hosts, such as farm and wild mammals, and birds. Campylobacter infections result mostly from oral ingestion of contaminated food or water. The frequent presence of Campylobacter in undercooked food and raw milk or dairy products indicates its risk of zoonotic transmission to humans (Bolton, 2015; Chlebicz \& Śliżewska, 2018; Chukwu et al., 2019).

Epidemiologically, Campylobacter has been estimated to be responsible for diarrhea affecting 400-500 million people with 37,600 deaths worldwide annually (Mughal, 2018; WHO, 2018). However, much of its epidemiological aspects in middle east countries are still unknown (Kaakoush et al., 2015). Transmission of Campylobacter from its natural reservoirs occurs mostly via contaminated food and water, person-to-person, and contact with infected animals (Kaakoush et al., 2015; Backert et al., 2017). Around 80\% of campylobacteriosis cases are transmitted by food. Raw milk-associated outbreaks are reported from different countries (Burakoff et al., 2018; Castrodale et al., 2013; Evans et al., 1996; Heuvelink et al., 2009; Korlath, et al., 1985; Longenberger et al., 2013; Mungai, et al., 2015; Porter \& Reid, 1980; Weltman et al., 2013).

Several Campylobacter species have been implicated in human infections, with $95 \%$ of infections due to $C$. jejuni, C. coli, and $C$. fetus (Kaakoush et al., 2015; Backert et al., 2017). However, other species are also known as gastrointestinal pathogen in both developing and developed countries such as C. lari, C. helveticus, C. upsaliensis, C. hominis, C. gracilis, C. lanienae, $C$. peloridis, C. concisus, C. mucosalis, $C$. hyointestinalis, C. sputorum, C. insulaenigrae, C. curvus, C. rectus, C. showae, and C. ureolyticus (Nachamkin \& Fitzgerald, 2015).

After an incubation period of usually 3 days, human campylobacteriosis manifests by gastroenteritis and other extraintestinal manifestations, mostly as sequelae. The gastrointestinal symptoms include abdominal pain, vomiting, acute watery or bloody diarrhea especially in toddlers under 3 years as well as in elderly accompanied by fever, dehydration, and nausea. Other complica-
Correspondence: Dhary Alewy Almashhadany, Knowledge University Research Center, EBL 446015, University Park, Kirkuk Road, Kurdistan Region, Iraq. Tel.: +9647733565479

E-mail: dhary.hammed@Knu.edu.iq

Key words: C. jejuni, C. coli, Antimicrobial susceptibility, Kurdistan region, Retail vending.

Conflict of interest: The author declares the absence of conflict of interest.

Funding: This work was supported by Knowledge University.

Availability of data and materials: All data are available within the text.

Received for publication: 30 September 2020 Revision received: 9 December 2020.

Accepted for publication: 11 December 2020,

This work is licensed under a Creative Commons Attribution-NonCommercial 4.0 International License (CC BY-NC 4.0).

(C) Copyright: the Author(s), 2021

Licensee PAGEPress, Italy

Italian Journal of Food Safety 2021; 10:8589 doi:10.4081/ijfs.2021.8589

tions include septicemia, urinary tract infections (UTI), reactive arthritis, GuillainBarre syndrome, and Miller-Fisher syndrome, among others (Backert et al., 2017).

In Kurdistan region Iraq, raw milk and dairy products are most commonly served in food outlets especially in retail vending, restaurants, street vendors, school, hotel, canteen and also in small outlets. No information available or published data on Campylobacter contamination level in milk or other dairy products in Erbil governorate. Therefore, this work was conducted in order to monitor the prevalence, biotypes, and antimicrobial susceptibility of Campylobacter spp. in raw milk sold at retail vending in Erbil city.

\section{Materials and Methods}

\section{Study design and sampling}

A total of 350 raw milk samples (120 cattle, 115 sheep, and 115 goats) were collected under aseptic conditions during January to June 2019 in Erbil city according to previously published method (Kazemeini, et al., 2011). Samples were transported in cooled bags within approximately half an hour to the Research Center Laboratory, Knowledge University. 


\section{Isolation of Campylobacter spp.}

Samples were process according to previously published isolation method (Salihu et al., 2010). In brief, $p \mathrm{H}$ of milk samples was adjusted to 7.5 and $20 \mathrm{ml}$ of milk was centrifugation at $14,000 \mathrm{rpm}$ for $20 \mathrm{~min}$. at $4^{\circ} \mathrm{C}$. The pellet was suspended in $45 \mathrm{ml}$ of Brucella broth base containing Butzler supplement (HiMedia, India) and 5-7\% (v/v) lysed horse blood in $100 \mathrm{ml}$ sterile flask, mixed properly and incubated at microaerophilic environment $\left(85 \% \mathrm{~N}_{2}, 5 \%\right.$ $\mathrm{O}_{2}$ and $10 \% \mathrm{CO}_{2}$ ) at $42^{\circ} \mathrm{C}$ for $48 \mathrm{~h}$. After the enrichment, a loopful of enriched culture was streaking on Campylobacter agar plates containing Butzler supplement (HiMedia, India) and $5-7 \%(\mathrm{v} / \mathrm{v})$ lysed horse blood. The inoculated plates were incubated at microaerophilic atmosphere at $42^{\circ} \mathrm{C}$ for 48 h. For purification, suspected colonies showing a typical drop-like appearance were further subcultured on the same medium and on blood agar with 5\% defibrinated sheep blood and incubated for $24 \mathrm{~h}$ at $37^{\circ} \mathrm{C}$ in microaerophilic conditions (Al-Dulaimi, 2013).

\section{Identification of Campylobacter species}

Campylobacter species was identified by colonies morphological characteristic on the plate, modified Gram stain (by counterstaining the smear with safranin for $3 \mathrm{~min}$ utes and use of carbol fuchsin instead of safranin stain), motility test by wet mount smear, and biochemical tests; catalase, oxidase, urease, growth in $3.5 \% \mathrm{NaCl}$, TSI reaction and growth on MacConky's agar (Marinou et al., 2012).

\section{Biotyping tests}

All biotyping reactions were performed according to standard methods described in MacFaddin manual (MacFaddin, 2000), unless stated otherwise.

\section{Growth at 25, 37 and $42^{\circ} \mathrm{C}$}

Campylobacter isolates were streaked on Campylobacter selective agar plates, and were divided into three groups. First group were incubated in $25^{\circ} \mathrm{C}$, the second in $37^{\circ} \mathrm{C}$ and the third in $42^{\circ} \mathrm{C}$ for 48 hours in microaerophilic conditions (Marinou et al., 2012).

\section{Cephalothin and nalidixic acid sus- ceptibility}

A Muller Hinton agar plates were evenly inoculated and two discs were placed on the agar surface, one of cephalothin $(30 \mu \mathrm{g})$ and the other was nalidixic acid $(30 \mu \mathrm{g})$. After the incubation period, sensitivity to nalidixic acid and cephalothin was inferred by a zone of clearing (Medeiros \& Hofmann, 2002).

\section{DNA hydrolysis test}

DNA agar plates (HiMedia, India) were inoculated and incubated at $37^{\circ} \mathrm{C}$ for $24-48$ hours. Campylobacter jejuni biotype IV, $C$. coli biotype II and $C$. lari biotype II, produce DNase and lyse medial DNA, but other biotypes show negative reaction.

\section{$\mathrm{H}_{2} \mathrm{~S}$ production}

Hydrogen sulfide production was tested by two methods; Triple Sugar Iron (TSI) medium and lead acetate paper. All isolates were subjected to $\mathrm{H}_{2} \mathrm{~S}$ production by leads acetate method.

Hippurate hydrolysis test: C. jejuni gives a positive result of this test, while all other species are negative.

\section{Antibiotics susceptibility testing}

Modified Kirby-Bauer disk diffusion method was employed to evaluate the susceptibility of Campylobacter isolates to twelve antibiotics according to CLSI guidelines (CLSI, 2011). The Enterobacteriaceae breakpoints published by CLSI were used to interpret the inhibition zones diameters around antibiotic disks. The tested antibiotics (Mast diagnostics, UK) were: amoxicillin, ampicillin, cephalothin, cefotaxime, ciprofloxacin, erythromycin, gentamycin, neomycin, rifampicin, streptomycin, and trimethoprim.

\section{Statistical analysis}

Data were analyzed via version 21 of SPSS software (SPSS Inc., Chicago). Confidence intervals were calculated by normal approximation method. Differences between groups were evaluated by Chi square test at alpha level of 0.05 .

\begin{tabular}{lccc} 
Type of milk & No. of samples & No. positive (\%) & $95 \%$ CI \\
Cow milk & 120 & $19(15.8)$ & $9.27-22.33$ \\
Sheep milk & 115 & $11(9.6)$ & $4.22-14.98$ \\
\hline Goats milk & 115 & $14(12.2)$ & $6.22-18.18$ \\
Total & 350 & $44(12.6)$ & $9.12-16.08$ \\
\hline
\end{tabular}

Table 2. Species of Campylobacter isolated from raw milk samples.

\begin{tabular}{lccc} 
Biotypes & No. of isolates & \% of isolates & $95 \% \mathrm{CI}$ \\
C. jejuni & 29 & 65.91 & $51.9-79.92$ \\
C. coli & 7 & 15.91 & $5.1-26.72$ \\
\hline C. lari & 3 & 6.82 & $0.00-14.27$ \\
C. fetus & 4 & 9.09 & $0.6-17.58$ \\
\hline C. gracilis & 1 & 2.27 & $0.00-6.67$ \\
Total & 44 & 100 & 100 \\
\hline
\end{tabular}

\section{Results}

\section{Prevalence of Campylobacter spp.}

Out of 375 raw milk samples, $12.6 \%$ were positive for the presence of Campylobacter spp. (Table 1). Up to $15.8 \%$ of the positive samples were derived from cow milk. Based on statistical inference, it is estimated that $9.12 \%$ to $16.08 \%(95 \%$ confidence interval) of raw milk sold in Erbil retail markets is contaminated by Campylobacter species. There is no significant difference between milk types in terms of Campylobacter occurrence $\left(\chi^{2}=0.985\right.$, $p=0.370$ ).

\section{Detected Campylobacter spp. and biotypes}

The detected species of Campylobacter isolated from raw milk are summarized in Table 2. C. jejuni was the most common species comprising $65.9 \%(29 / 44)$ of the total isolates. Three biotypes of $C$. jejuni were detected; biotype II (24.2\%), biotype III $(17.2 \%)$, and biotype IV which was the most common (58.6\%). Only the biotype II of $C$. coli was found, while two biotypes of C. lari were detected; biotype I (66.7\%) and biotype II (33.3\%). C. jejuni is significantly more prevalent species in milk samples than other Campylobacter species $(p=0.0195)$.

\section{Temporal distribution of Campylobacter spp.}

The change in prevalence rate of Campylobacter species was monitored isolation was observed in June $(25.0 \% \%)$ throughout study period. The highest rate of

Table 1. Prevalence of Campylobacter species among raw milk samples. 
and May $(20.3 \% \%)$, while the lowest rate was found in February (3.4\%). Table 3 summarizes detected proportions in temporal scale. There is a good association ( $22=$ 0.8397) between Campylobacter presence in milk and warm season progress (spring summer) (Figure 1).

\section{Antimicrobial susceptibility of Campylobacter spp.}

Campylobacter isolates $(\mathrm{n}=44)$ were evaluated against a panel of twelve commonly used antibiotics. The results of antimicrobial susceptibility testing showed a complete resistance to ampicillin and trimethoprim. On the contrary, total sensitivity was found to neomycin, rifampicin and tetracycline. The detailed antibiogram profile is summarized in Figure 2.

\section{Discussion}

Campylobacter is an important etiology in gastrointestinal bacterial outbreaks worldwide. According to the European Centers for Disease Control and Prevention (ECDC) and the Global Enteric Multicentre Study (GEMS), Campylobacter spp. are now considered to be the leading cause of bacterial gastroenteritis worldwide with higher occurrence rates in children under 5 years old (ECDC, 2019; Levine et al., 2012). The overall prevalence of Campylobacter spp. found in the present study is $12.6 \%$. These results are consistent with a previous study in Pakistan which found the highest occurrence (11.6\%) of Campylobacter in butter and raw milk (Mahmood et al., 2009). Additionally, similar prevalence rates ranging from $12 \%$ to $18 \%$ were also reported from Italy (Bianchini et al., 2014), Tanzania (Kashoma et al., 2016), and Yemen (AlZailay, 2017). However, lower rates were also reported in other studies from Iran (6.25\%) (Rahimi, Sepehri, \& Momtaz, 2013), Turkey (7.2\%) (Elmalı et al., 2019), Egypt (4.44\%) (Barakat et al., 2015), and India (2.9\%) (Modi et al., 2015). These variations may be attributed to differences in geographical locations, sensitivity of detection method, level of hygiene, food practice, availability of natural reservoirs of Campylobacter, among other factors
(Kaakoush et al., 2015). Regarding Campylobacter spp. isolated in this study (Table 2), C. jejuni was the most prevalent $(65.9 \%)$ which is consistence with previous studies from Iran (Rahimi et al., 2013),

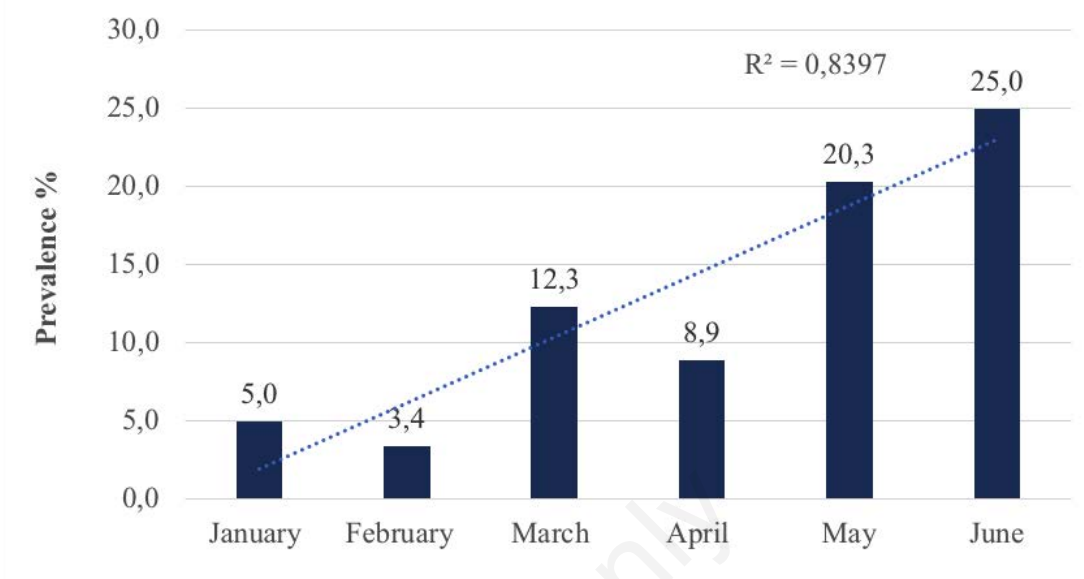

Figure 1. Association between months and prevalence of Campylobacter spp. in raw milk.

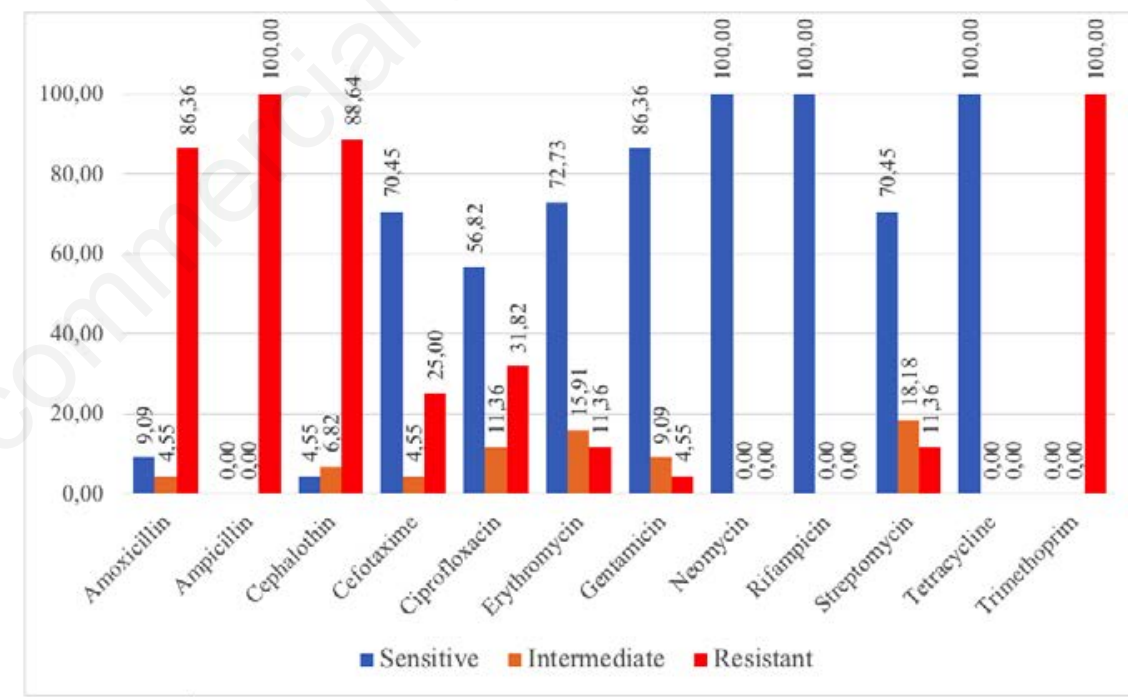

Figure 2. Antibiogram profile of Campylobacter spp. against twelve antibiotics.

Table 3. Temporal distribution of Campylobacter spp. during study period.

\begin{tabular}{lccccc} 
Month & \multicolumn{2}{c}{ No. of examined milk (no. of positive) } & Total examined & Total positive (\%) \\
January & Sheep & $22(0)$ & $18(1)$ & 60 & $3(5.0)$ \\
February & $22(2)$ & $19(1)$ & $19(0)$ & 58 & $2(3.4)$ \\
\hline March & $20(1)$ & $19(2)$ & $19(3)$ & 57 & $7(12.3)$ \\
April & $19(2)$ & $18(1)$ & $20(1)$ & 56 & $5(8.9)$ \\
May & $18(3)$ & $20(3)$ & $19(4)$ & 59 & $12(20.3)$ \\
June & $20(5)$ & $19(4)$ & $20(5)$ & 60 & $15(25.0)$ \\
Total & $21(6)$ & $115(11)$ & $115(14)$ & 350 & $44(12.6)$ \\
\hline
\end{tabular}


Tanzania (Kaakoush et al., 2015), Yemen (Al-Zailay, 2017), and Turkey (Elmalı et al., 2019). A very recent study in Iraq (Kanaan, 2018) has found that two distinct biotypes (I \& II) of two Campylobacter species; $C$. jejuni and $C$. coli to be the most prevalent biotypes. Additionally, biotype II of $C$. coli was the most common (25\%) biotype of the species. However, biotypes I of each species were detected in the present work. The observation that $C$. jejuni and $C$. coli biotype I dominate in humans, while biotype II was more prevalent in animals suggests that the contaminating source of milk is most probably the domesticated animals including the animals from which samples were drawn.

In terms of time-based prevalence of Campylobacter, the highest occurrence was documented in late spring and early summer, while the lowest rate was found in winter (Table 3 ). These observations are in good line with a Nigerian study that reported that the number of campylobacteriosis peaks on summer seasons and then decline in winter season (Salihu et al., 2010). Several studies had connected warm periods to high prevalence of Campylobacter (Zeleňáková et al., 2012), Germany (Schielke et al., 2014), Egypt (Omara et al., 2015), and Lebanon (Ibrahim et al., 2019). The underlying reason behind this seasonality is still unclear, but may indicate a possible association between temperature and Campylobacter survival and transmission of infection (Jorgensen et al., 2011; Patrick et al., 2004).

The antibiogram profile showed complete resistance $(100 \%)$ to ampicillin and trimethoprim, while total sensitivity was recorded to neomycin, rifampicin, and tetracycline (Figure 2). There are wide variations in antibiotic resistance pattern of Campylobacter isolates in published literature from different countries around the globe. For instance, ciprofloxacin resistance level found in the present work is in good agreement with previously reported (30.77\% and 34.4\%) in Iran (Maktabi et al., 2019; Rahimi et al., 2013). However, the high sensitivity to gentamicin and streptomycin found in this study is lower than reported from India (Modi et al., 2015). The resistance levels to ampicillin, erythromycin, and gentamicin are also in good agreement with a recent Tanzanian study of beef carcasses and raw milk samples (Kashoma et al., 2016). These variations in resistance phenotypes are influenced by strains thriving in different ecological niches, geographical locations, antibiotic uses, and horizontal gene transfer of resistance determinants (Luangtongkum et al., 2009; Shen et al., 2018).

\section{Conclusions}

Campylobacter species prevalence in raw milk is moderately high in Erbil city, which may pose a serious threat to consumers. Warm season (summer) was found to be associated with increase in Campylobacter prevalence in raw milk samples. Fortunately, the isolates still have accepted sensitivity level to the drug of choice in treatment of campylobacteriosis (Macrolides, tetracyclines, and aminoglycosides). The high occurrence of Campylobacter spp. in raw milk could be reduced by improvement of sanitary condition applied during milking, handling, storage, and also by increase awareness of farmers and retailers. A four-season study is highly recommended to investigate the distribution of campylobacters in raw milk accompanied by antibiotic susceptibility testing to aid in control of burden and morbidity of campylobacteriosis.

\section{References}

Al-Dulaimi FM, 2013. Prevalence of Campylobacter species in faeces of children and poultry meats in Dhamar province. MSc thesis, Sana'a University, Yemen.

Al-Zailay FMA, 2017. Epidemiological study on campylobacteriosis in human and cow raw milk at Dhamar governorate, Yemen. MSc thesis, Thamar University, Yemen.

Backert S, Tegtmeyer N, Cróinín TÓ, Boehm M, Heimesaat MM, 2017. Human campylobacteriosis. In: Klein G, editor. Campylobacter: Features, Detection, and Prevention of Foodborne Disease. Academic press, London, pp $1-25$.

Barakat AM, Sobhy MM, El Fadaly HA, Rabie NS, Khalifa NO, Hassan E, Kotb M, Amin Girh Z, Sedeek D, Zaki M, 2015. Zoonotic hazards of campylobacteriosis in some areas in Egypt. Life Sci J 12:9-14.

Bianchini V, Borella L, Benedetti V, Parisi A, Miccolupo A, Santoro E, Recordati C, Luini M, 2014). Prevalence in bulk tank milk and epidemiology of Campylobacter jejuni in dairy herds in Northern Italy. Appl Env Microbiol 80:1832-7.

Bolton DJ, 2015. Campylobacter virulence and survival factors. Food Microbiol 48:99-108.

Burakoff A, Brown K, Knutsen J, Hopewell C, Rowe S, Bennett C, Cronquist A, 2018. Outbreak of fluoroquinolone- resistant Campylobacter jejuni infections associated with raw milk consumption from a Herdshare Dairy Colorado, 2016. MMWR 67:146-8.

Castrodale LJ, Gerlach RF, Xavier CM, Smith BJ, Cooper MP, Mclaughlin JB, 2013. Sharing milk but not messages: campylobacteriosis associated with consumption of raw milk from a cowshare program in Alaska, 2011. J Food Prot 76:744-7.

Chlebicz A, Śliżewska K, 2018. Campylobacteriosis, salmonellosis, yersiniosis, and listeriosis as zoonotic foodborne diseases: a review. Int J Env Res Public Health 15:863.

Chukwu, MO, Luther King Abia ALK, Ubomba-Jaswa E, Obi L, Dewar JB, 2019. Characterization and phylogenetic analysis of campylobacter species isolated from paediatric stool and water samples in the Northwest province, South Africa. Int J Env Res Public Health 16:2205.

CLSI (Clinical and Laboratory Standards Institute), 2011. Performance Standards for Antimicrobial Susceptibility Testing; Twenty-First Informational Supplement. M100-S21. Wayne, Pennsylvania.

European Centre for Disease Prevention and Control (ECDC). Campylobacteriosis Annual Epidemiological Report for 2017.Stockholm: ECDC; 2019. Available from: https://www.ecdc.europa.eu/sites/defau 1t/files/documents/AER_for_2017campylobacteriosis.pdf

Elmalı M, Can HY, 2019. Antimicrobial susceptibility and virulence-associated genes in Campylobacter isolates from milk and wastewater in Hatay, Turkey. Ciência Rural 49

Evans MR, Roberts RJ, Ribeiro CD, Gardner D, Kembrey D, 1996. A milkborne Campylobacter outbreak following an educational farm visit. Epidemiol Infect 117:457-62.

Heuvelink AE, van Heerwaarden C, Zwartkruis-Nahuis A, Tilburg JJ, Bos MH, Heilmann FG, Hofhuis A, Hoekstra T, de Boer E, 2009. Two outbreaks of campylobacteriosis associated with the consumption of raw cows' milk. Int J Food Microbiol 134:70-4.

Ibrahim JN, Eghnatios E, El Roz A, Fardoun T, Ghssein G, 2019. Prevalence, antimicrobial resistance and risk factors for campylobacteriosis in Lebanon. J Infect Devel Countr 13:11-20.

Isabel R, 2019. Campylobacter jejuni bacteremia in a patient with asplenia and 
enteritis. IDCases 17, e00555.

Jorgensen F, Ellis-Iversen J, Rushton S, Bull SA, Harris SA, Bryan SJ, Gonzalez A, Humphrey TJ. (2011). Influence of season and geography on Campylobacter jejuni and C. coli subtypes in housed broiler flocks reared in Great Britain. Appl Env Microbiol 77:3741-8.

Kaakoush NO, Castaño-Rodríguez N, Mitchell HM, Man SM, 2015. Global epidemiology of Campylobacter infection. Clin Microbiol Rev 28:687-20.

Kanaan MH, 2018. Biotyping and resistotyping of Campylobacter isolates recovered from frozen chicken meat sold in Baghdad province. Int J Sci Res 7:3046.

Kashoma IP, Kassem II, John J, Kessy BM, Gebreyes W, Kazwala RR, Rajashekara G, 2016. Prevalence and antimicrobial resistance of Campylobacter isolated from dressed beef carcasses and raw milk in Tanzania. Microb Drug Resist 22:40-52.

Kazemeini H, Valizade Y, Parsaei P, Nozarpour N, Rahimi E, 2011. Prevalence of Campylobacter species in raw bovine milk in Isfahan, Iran. Middle-East J Sci Res 5:664-6.

Korlath JA, Osterholm MT, Judy LA, Forfang JC, Robinson RA, 1985. A Point-source outbreak of campylobacteriosis associated with consumption of raw milk. J Infect Dis 152:592-6.

Levine MM, Kotloff KL, Nataro, JP, Muhsen K, 2012. The Global Enteric Multicenter Study (GEMS): Impetus, rationale, and genesis. Clin Infect Dis 55:S215-24.

Longenberger AH, Palumbo AJ, Chu AK, Moll ME, Weltman A, Ostroff SM, 2013. Campylobacter jejuni infections associated with unpasteurized milkmultiple states, 2012. Clin Infect Dis 57:263-6.

Luangtongkum T, Jeon B, Han J, Plummer P, Logue CM, Zhang Q, 2009. Antibiotic resistance in Campylobacter: emergence, transmission and persistence. Future Microbiol 4:189-200.

MacFaddin JF, 2000. Biochemical Tests for the Identification of Medical Bacteria. 3rd ed. Lippincott, Williams \& Wilkins Co, Philadelphia, PA, USA.

Mahmood MS, Hussain I, Arshad MI, Ali S, Aktar M, Khan A, Mahmood F, 2009. Seasonal prevalence of Campylobacter species in milk and milk products in Pakistan. Pak J Zool Suppl Ser 9:22731.

Maktabi S, Ghorbanpoor M, Hossaini M, Motavalibashi A, 2019. Detection of multi-antibiotic resistant Campylobacter coli and Campylobacter jejuni in beef, mutton, chicken and water buffalo meat in Ahvaz, Iran. Vet Res Forum 10:37-42.

Marinou I, Bersimis S, Ioannidis A, Nicolaou C, Mitroussia-Ziouva A, Legakis NJ, Chatzipanagiotou S, 2012. Identification and antimicrobial resistance of Campylobacter species isolated from animal sources. Front Microbiol 3:58.

Medeiros D, Hofmann L, 2002. Isolation of thermophilic Campylobacter from food, MFLP-46. Ottawa, Canada.

Modi S, Brahmbhatt MN, Chatur YA, Nayak JB, 2015. Prevalence of Campylobacter species in milk and milk products, their virulence gene profile and antibiogram. Vet World 8:1-8.

Mughal MH, 2018. Campylobacteriosis: a global threat. Biomed J Sci Tech Res 11:001-5.

Mungai EA, Behravesh CB, Gould LH, 2015. Increased outbreaks associated with nonpasteurized milk, United States, 2007-2012. Emerg Infect Dis 21:119-22.

Nachamkin I, Fitzgerald C, 2015. Campylobacter and Arcobacter. In: Jorgensen JH, Pfaller MA, eds. Manual of Clinical Microbiology, $11^{\text {th }}$ edn. ASM press, Washington DC, pp 9981012.

Omara ST, Fadaly HA, Barakat AMA,
2015. Public health hazard of zoonotic Campylobacter jejuni reference to Egyptian regional and seasonal variations. Res J Microbiol 10:343-54.

Patrick ME, Christiansen LE, Wainø M, Ethelberg S, Madsen H, Wegener HC, 2004. Effects of climate on incidence of Campylobacter spp. in humans and prevalence in broiler flocks in Denmark. Appl Env Microbiol 70:7474-80.

Porter IA, Reid TMS, 1980. A milk-borne outbreak of Campylobacter infection. J Hyg 84:415-9.

Rahimi E, Sepehri S, Momtaz H, 2013. Prevalence of Campylobacter species in milk and dairy products in Iran. Evue Med Vet 164:283-8.

Salihu MD, Junaidu AU, Magaji AA, Rabiu ZM, 2010. Study of Campylobacter in raw cow milk in Sokoto state, Nigeria. Br J Dairy Sci 1:1-5.

Schielke A, Rosner BM, Stark K, 2014. Epidemiology of campylobacteriosis in Germany - insights from 10 years of surveillance. BMC Infect Dis 14:30.

Shen Z, Wang Y, Zhang Q, Shen J, 2018. Antimicrobial resistance in Campylobacter spp. Microbiol Spec 6.

Weltman A, Longenberger AH, Moll M, Johnson L, Martin J, Beaudoin A, 2013. Recurrent outbreak of Campylobacter jejuni infections associated with a raw milk dairy - Pennsylvania, April-May 2013. Available from https://stacks.cdc.gov/view/cdc/54694

WHO 2018. Campylobacter. Retrieved September 25, 2019, from https://www.who.int/news-room/factsheets/detail/campylobacter

Zelenáková L, Ziarovská J, Kozelová D, Mura L, Lopasovský L, Bobková A, Zajác P, Capla J, Tináková K, 2012. Campylobacteriosis: importance of strengthening surveillance and reported foodborne disease control within European Union. J Microbiol Biotechnol Food Sci 1:855-867. 